\title{
Los contenidos editoriales como herramienta determi- nante para construir una marca: el caso de El Mundo
}

\section{Editorial Content as Determining Tool for Brand Building: The case of El Mundo}

Mónica Herrero, profesora de Empresa Informativa. Universidad de Navarra

Juan Pablo Artero, profesor de Empresa Informativa. Universidad de Navarra

Alfonso Sánchez-Tabernero, catedrático de Empresa Informativa. Universidad de Navarra

Recibido: 9-XII-2008 - Aceptado: 25-II-2009

Resumen:

El diario El Mundo se lanzó en Madrid en 1989. Las circunstancias externas no eran muy propicias: entre otras, la empresa editora no tenía capital suficiente ni plantas de impresión propias; además disponía de una plantilla muy reducida. Sin embargo El Mundo consiguió superar los obstáculos y convertirse en el segundo diario de mayor circulación en España. La clave del éxito ha sido su oferta editorial: el valor de denunciar casos de corrupción política y económica y su independencia respecto a los anunciantes y los partidos políticos. A lo largo de este artículo se analizarán los principales atributos de la marca y de la oferta editorial de El Mundo. Para ello, además de la revisión de la literatura pertinente, se han mantenido entrevistas con los directivos y se ha acudido a los estudios de marca que realiza el departamento de marketing del periódico entre sus lectores.

Palabras clave:

Gestión editorial, liderazgo, prensa general, contenidos

Abstract:

The daily newspaper "El Mundo" ("The World") was launched in Madrid in 1989. The external circumstances were really discouraging: The publishing company did not have enough capital, it did not own printing facilities and the journalistic crew was too short. However, "El Mundo" did managed to surpass these obstacles and has turned into the second best-selling general information newspaper in Spain. The key success factor of "El Mundo" has been its editorial bid: its valor to denounce cases of political and economic corruption; its independence from advertisers and the main political parties. In this research paper, the main editorial bids and brand attributes of "El Mundo" are analyzed. In order to reach this aim, interviews will be held with the main managers of the newspaper and the brand research reports that the marketing department prepares will also be studied.

Key words:

Editorial management, leadership, general press, media contents 


\section{Introducción}

En 2006, Unidad Editorial, la empresa editora de El Mundo, obtuvo un resultado bruto de explotación (EBITDA) de 60 millones de euros; sus ingresos netos ascendieron a 350 millones de euros, la publicidad facturada superó los 140 millones de euros y el diario alcanzó los 330.000 ejemplares vendidos de media, lo que le situaba -tras El País-en la segunda posición de los diarios de información general, cada vez a menos distancia de su principal competidor en el mercado.

El éxito de la versión on line del periódico era aún mayor: elmundo.es superó en ese ejercicio económico la cifra media de nueve millones de usuarios únicos y 264 millones de páginas vistas, un 30\% más que elpais.com, que ocupaba el segundo lugar del ranking. En los últimos años, Unidad Editorial también había tomado posiciones en otros sectores de la comunicación: edición de revistas y libros, producción audiovisual y televisión digital terrestre.

En junio de 2007, la Junta General de accionistas aprobó la adquisición de Recoletos, un grupo dedicado a la edición de publicaciones especializadas, que durante unos años fue propiedad de Pearson, y que era líder destacado en los sectores de la prensa deportiva con el diario Marca, de la prensa económica con el diario Expansión y de la prensa médica y farmacéutica con los diarios gratuitos Diario Médico y Correo Farmacéutico. En esa Junta General, con cierta euforia por la acumulación de buenas noticias, el director de $E l$ Mundo proclamó: “Cuando termine el año, nuestra realidad será el grupo de prensa escrita y electrónica más importante del mundo en lengua castellana” (El Mundo, 2007:68).

El ejercicio del 2007 (seis meses después de la fusión) se cerraba con unos resultados todavía mejores. La difusión se incrementaba en un $1.71 \%$ respecto al año anterior, superando el crecimiento de El País, que se cifraba en un $0.67 \%$ y alcanzando los 336.000 ejemplares, la cifra record de difusión de su historia. El EBITDA alcanzaba los 128 millones de euros (incluyendo los 59,8 correspondientes a Recoletos), y los ingresos netos sumaban 628,8 millones de euros (incluidos los 251,1 de Recoletos).

A lo largo de este artículo se estudiarán los elementos que han contribuido a construir la marca de éxito del periódico y la consiguiente expansión y crecimiento del grupo multimedia Unidad Editorial. Se revisará la literatura pertinente y se aportarán datos de las encuestas realizadas por CIMOP a los lectores del diario. 


\section{El Mundo, un diario contra corriente}

\subsection{Génesis del diario}

La trayectoria de El Mundo comenzó en Madrid en 1989. Las circunstancias en las que nació el periódico no podían ser más desalentadoras: la empresa no contaba con capital suficiente, no disponía de rotativa propia y su plantilla de redactores era escasa; la difusión de los diarios en España se encontraba estancada; los principales rivales en la prensa nacional -El País y ABC-ocupaban un sólido liderazgo entre lectores de centro-izquierda y centro-derecha respectivamente; los intentos de lanzar nuevos diarios en Madrid durante los años anteriores habían fracasado; y la aparición a los pocos meses de los tres primeros canales privados de televisión incrementaba la competencia en el mercado publicitario.

La aparición de El Mundo obedece indirectamente a la intromisión excesiva del poder político en la prensa: el diario madrileño Diario 16 llevaba varios meses denunciando -con frecuencia en su primera página- algunos casos de corrupción en el Gobierno socialista de Felipe González. Sus competidores, en cambio, o bien dedicaban poco espacio a esas noticias o, sin más, las ignoraban.

El Gobierno presionó a la empresa para que dejara de publicar esas informaciones y cesara al director. Los propietarios de Diario 16 se encontraban en una posición débil, porque llevaban años perdiendo dinero y tenían una deuda grande con el Estado; por ese motivo, decidieron rebajar el tono de sus críticas al Gobierno y cesaron al carismático director de Diario 16, Pedro J. Ramírez. De modo paradójico, esos hechos se produjeron cuando el diario -como consecuencia de su valentía para denunciar los casos de corrupción- había alcanzado su récord de difusión, con una media de 145.000 ejemplares, y parecía estar a punto de entrar en rentabilidad.

Para Ramírez, su destitución constituía un ataque a la libertad de expresión y una prueba de la debilidad de la democracia española. Con este mensaje, repetido de modo insistente en entrevistas en diversos medios, se lanzó a una aventura que parecía suicida: lanzar un nuevo periódico, que conservara el espíritu genuino de Diario 16 y no se dejara maniatar por el poder político. Ramírez convenció a algunos de los directivos más destacados de Diario 16 para que le acompañasen en su proyecto: Alfonso de Salas, Balbino Fraga y Juan González, que se ocuparían respectivamente de la dirección general, la gestión publicitaria y la dirección financiera del nuevo diario.

El 23 de octubre salía a la calle El Mundo, con la legitimidad de enarbolar la bandera que había llevado hasta entonces Diario 16. Junto a Ramírez, ocuparon puestos claves en la redacción de El Mundo seis periodistas 
que provenían de Diario 16: Juan Carlos Laviana, director de información, encargado del control de calidad del periódico; Manuel Hidalgo, director adjunto de opinión; Alfonso Rojo, corresponsal en los principales conflictos bélicos del mundo; Melchor Miralles, director del equipo de periodismo de investigación; Carmelo Caderot, director de arte; y Jorge Fernández, subdirector. Como explica el director, "ese grupo de seis personas (...) constituyó desde el principio la base del equipo directivo del periódico. Ellos componen lo que hemos dado en llamar 'el directorio de El Mundo'” (Ramírez, 1991: 400).

Además, al día siguiente al cese de Ramírez como director de Diario 16 dejaron de aparece en ese periódico otras firmas populares, como el columnista Paco Umbral o los caricaturistas Forges y Gallego \& Rey. Diario 16 perdía legitimidad por haber sucumbido a la presión del Gobierno y era abandonado por algunos de sus más prestigiosos profesionales, que constituían como sub-marcas que aportaban valor a la marca paraguas del periódico.

Pedro J. Ramírez era consciente de que el tiempo jugaba en su contra: aunque existía un cierto movimiento de simpatía hacia su "causa", el público olvidaría pronto los hechos si nadie les recordaba que el espíritu liberal de Diario 16 había sido aplastado por el Gobierno. Por ese motivo, el director destituido emprendió dos batallas: en primer término, consiguió una gran presencia en el debate político, con entrevistas, artículos y reportajes en los que daba cuenta de su proyecto; en segundo término se lanzó a una rápida carrera para poner cuanto antes un nuevo diario en la calle.

En efecto, en la fiesta de lanzamiento de El Mundo, Ramírez pudo afirmar ante los 4.000 invitados que abarrotaban el Planetario de Madrid, que su equipo había puesto en marcha un nuevo diario nacional en poco más de siete meses. En ese tiempo, los promotores del proyecto habían sido capaces de buscar financiación, elaborar un proyecto editorial, configurar la plantilla, llegar a acuerdos comerciales con proveedores, distribuidores e impresores, y realizar la campaña de lanzamiento.

\subsection{El éxito inicial}

Como explicaba uno de sus competidores, El Mundo apareció un día antes de lo que había previsto su equipo directivo, "para que el primer número del diario pudiese publicar una encuesta sobre las expectativas de voto (...) en el último día permitido por la legislación electoral para la publicación de sondeos sobre intención de voto" (Mardones, 1989: 38).

Unidad Editorial destinó a la campaña de lanzamiento del diario 300 millones de pesetas, es decir, casi el $20 \%$ del capital propio invertido por los accionistas. Los directivos pensaban que debían asumir ese riesgo 
inicial, que permitiría aprovechar el escándalo producido por los despidos de Diario 16 y la corriente de simpatía hacia el proyecto de creación de un nuevo periódico. El lema de la campaña de lanzamiento fue "Información sobresaliente": en los anuncios se aseguraba que El Mundo ofrecería un contenido que sus rivales no se atrevían a publicar, porque sólo él estaba libre de censuras y cobardías (García Alonso, 1995, 54).

El Mundo apareció en los kioscos con 120 páginas, con un diseño atractivo y un lenguaje directo. El primer día vendió 250.000 ejemplares, aunque pronto su difusión se estabilizó en torno a los 100.000. En diciembre de 1990, la Oficina de Control de Difusión española publicó los datos de ventas correspondientes a los primeros seis meses de ese año: 104.000 ejemplares. "Esas cifras -señalaba el director del periódico- se recibieron con gran euforia en la Redacción, porque prácticamente duplicaban los objetivos que el presupuesto había fijado para el primer año. De hecho, había que remontarse al lanzamiento de El País en los momentos mágicos del inicio de la transición para encontrar una cifras de difusión equivalentes" (Ramírez, 1991: 452).

En efecto, el lanzamiento más exitoso en la prensa española de las últimas décadas lo había protagonizado en 1976 El País, en plena convulsión política, social y periodística provocada por el fallecimiento del General Franco: el diario editado por PRISA había logrado una difusión media de 117.000 ejemplares en su primer año (Edo, 1994).

Al éxito inicial de El Mundo contribuyó de manera determinante el entusiasmo del equipo humano: los promotores transmitieron a la Redacción y a los demás empleados la misma historia que querían contar a sus lectores: el Gobierno español había decidido acallar una voz crítica y los propietarios de Diario 16, atenazados por su fragilidad económica, habían sucumbido a la presión del poder político. Los periodistas de El Mundo percibían que su joven empresa era la respuesta a una injusticia y a un abuso de poder. Por tanto, trabajaban con gran motivación y con un notable grado de sintonía con el proyecto editorial.

En la gestación y en los primeros meses de vida de El Mundo ya se perfilan buena parte de los rasgos que van a configurar esa marca periodística: el periódico da prioridad a la cobertura del debate periodístico español; pretende cumplir una misión de contrapoder, que evite los excesos del Gobierno de la nación; explica a sus lectores esa tarea con un trasfondo épico, e intenta que se sumen a su causa; apuesta por historias a las que concede gran importancia, las investiga a fondo, las sigue durante mucho tiempo, aunque no abarque tantos temas noticiosos como sus principales rivales; actúa con flexibilidad, con sentido del tiempo y de la oportunidad, sin encajonarse en reglas o planes preestablecidos; y sabe que, en un mercado estancado, es tan importante encontrar nuevos lectores como desubicar y erosionar la credibilidad de los demás diarios nacionales. 


\section{El liderazgo carismático de Pedro J. Ramírez}

\subsection{El papel relevante del director}

La marca de El Mundo fue, en sus primeros años, muy dependiente de la figura de su director. Pedro J. Ramírez era quien había puesto en jaque al Gobierno socialista con la denuncia -primero desde Diario 16, y a partir de 1989 desde su nuevo diario- del “caso GAL”: un episodio de terrorismo de Estado, organizado para combatir a la banda armada ETA. Un editorial del Financial Times $(1993,4)$ reconocía la influencia de Ramírez en el panorama político español: "El principal responsable de que Felipe González, Presidente del Gobierno de España, haya tenido que convocar elecciones generales el 6 de junio (...) es un periodista, no un político. Pedro J. Ramírez, con su tenacidad, inteligencia y capacidad persuasiva, ha sido una espina para el gobierno socialista durante años".

El director de El Mundo, además, configuró un equipo adecuado para desarrollar su proyecto: algunas personas con experiencia en puestos claves de la gestión y de la Redacción, y una mayoría de periodistas muy jóvenes, recién salidos de la universidad y con cierto espíritu de aventura. En ese contexto, y con unas cifras de ventas en ascenso continuado, que indicaban la creciente aceptación por parte del público, el liderazgo de Ramírez era incuestionable.

La tarea del director no se reducía a la elaboración del periódico: Pedro J. Ramírez se había ocupado personalmente de buscar el capital inicial: había expuesto su idea a posibles inversores con el propósito de conseguir 500 millones de pesetas, pero al cabo de unos meses había reunido 1.700 millones. Tanto los accionistas que se incorporaron al proyecto como los bancos que concedieron los primeros créditos apostaron más por una persona que por un plan de negocios.

Las circunstancias del nacimiento de El Mundo reforzaron la posición de Ramírez: el principal activo era el director del periódico, que había sufrido el ataque del Gobierno, había elaborado el proyecto editorial, había seleccionado al equipo y había conseguido la financiación necesaria. Por tanto, cuando políticos, anunciantes o bancos intentaban influir en los contenidos informativos carecían de capacidad de presión, porque forzar la destitución del director podría suponer comprometer la supervivencia del periódico. De hecho, así estaba sucediendo con Diario 16, que tras la salida de Pedro J. Ramírez y del grupo de profesionales que se unió a él, inició un periodo de decadencia, que culminó con su cierre en 2001, tras perder 4.400 millones de pesetas en sus últimos cuatro años.

Desde su salida a la calle, el contenido de El Mundo ha dependido casi de modo exclusivo de la voluntad de su director y de su equipo. La principal clave de éxito del diario ha sido su apuesta editorial: la denuncia de 
casos de corrupción política y económica, su independencia de los anunciantes, las entidades financieras, los accionistas y los dos grandes partidos políticos españoles. En cierto modo, el diario ha querido protagonizar -así lo han manifestado sus directivos- una nueva historia de Robin Hood, devolviendo a los ciudadanos un gran bien confiscado por los más poderosos: la información libre, sin presiones ni censuras.

La narración de historias épicas está en la base de la construcción de muchas marcas (Arvidsson, 2005; Danesi, 2006), y así ha sucedido también en el caso de El Mundo. Ramírez pretendía que su diario sirviese como seña de identidad de los lectores, que al llevar bajo el brazo el ejemplar mostraban su simpatía hacia un proyecto, su apoyo a los esfuerzos del débil frente a los que abusan del poder. A través de las páginas del periódico y en entrevistas en otros medios, Ramírez afirmaba con insistencia que "El Mundo está en manos de sus lectores” o que “El Mundo es de sus lectores”, para recalcar la independencia del periódico. También recordaba que en el conflicto entre sumisión al poder y libertad de expresión, vencería la parte más débil, gracias a su astucia, coraje y determinación: desde esa perspectiva, parecía muy apropiada la comparación entre el director del periódico y el héroe de los bosques de Sherwood.

Como señala Holdt (2004), en el mundo de la comunicación las marcas se convierten en iconos culturales cuando defienden una causa atractiva que se comunica al público con metáforas impactantes, con ideas sencillas, con eslóganes fáciles de recordar. Las marcas también necesitan protagonistas que encarnen esas propuestas y les den vida. Ramírez ha cumplido esa misión, con la ventaja añadida de que la historia narrada no se refería a un hecho sucedido en el pasado; el combate entre dos fuerzas seguía vigente: por una parte, el poder que con el transcurso del tiempo se corrompe y trata de amordazar las voces críticas y, por otra, los defensores de la libertad de expresión. El director de El Mundo había identificado ya a los protagonistas -el gabinete de Felipe González y su propio diario- y conseguía encontrar motivos frecuentes de confrontación que aportaban actualidad y frescura a esa batalla.

Los lectores esperaban cada día que su periódico les sorprendiese con una nueva revelación, con un nuevo caso de corrupción política, con una nueva historia de abuso de poder. El Mundo presentaba esas primicias informativas como un ejemplo del compromiso con el público de Pedro J. Ramírez y su equipo: los lectores percibían que la Redacción no se sometía a presiones externas.

\subsection{Garantías de independencia}

El director de El Mundo estableció una garantía para fortalecer la independencia del periódico: el capital inicial de la compañía estaba muy diversificado. Los accionistas con mayor participación en el capital eran Francisco Gaya, con un 15\% de las acciones y la empresa editora del londinense The Guardian, con un 10\% 
(García Alonso, 1995). Al limitar el poder de cada propietario, era más fácil que la Redacción conservase el control total del contenido del diario. Además, los profesionales - periodistas y gestores- poseían un $25 \%$ del capital.

En 1991 se produjo una ampliación de capital destinada a la adquisición de activos materiales y a hacer frente a las pérdidas iniciales. Como resultado de esa operación, el grupo italiano Rizzoli-Corriere della Sera pasó a poseer el 45\% de las acciones, porcentaje que ampliaría en 2000 al 96\%. Sin embargo, los editores italianos se comprometieron a respetar la línea editorial del diario y a no cambiar al director al menos hasta el año 2007 (Noticias de la Comunicación, 1991). De esa forma, El Mundo aseguraba su supervivencia, mantenía su independencia y se beneficiaba de las sinergias generadas en uno de los mayores editores de diarios en Europa.

La orientación a ofrecer información exclusiva y crítica ha generado problemas económicos al periódico sobre todo en los primeros años, como algunos problemas en el control de costes o la pérdida de anunciantes importantes. Pero Pedro J. Ramírez ha encontrado un complemento extraordinario en Antonio Fernández Galiano, director gerente casi desde los inicios, que ha conseguido que la calidad informativa del diario sea compatible con la eficiencia económica.

La pasión del director de El Mundo por la independencia de la prensa arranca ya de sus primeros años como joven columnista político del diario $A B C$. En esa época publicó su primer libro, titulado Prensa y Libertad (Ramírez, 1980). Desde su fundación, El Mundo sólo ha tenido un director. Como explica Kung (2006), una de las piedras de toque del liderazgo consiste en preparar y llevar a cabo una sucesión sin traumas. Tras Ramírez, dirigirá la Redacción otro periodista, que imprimirá también su sello personal. Pero el diario ya está marcado por una apuesta editorial, un estilo, un tono, un enfoque, que obedecen a la personalidad de su actual director, y que en buena medida señalan su rumbo para los próximos años.

\section{Contenidos y construcción de la marca}

\subsection{Marca y prensa diaria}

Las empresas disponen de muy variadas herramientas para construir y proteger el valor de sus marcas (Aaker, 1991; Miller y Muir, 2004; Elliot y Percy, 2007): campañas publicitarias; relaciones públicas; patrocinio de actividades culturales y deportivas; foros de participación ciudadana; selección de los puntos de distribución; diseño y otros aspectos externos de la oferta (empaquetado); acuerdos y proyectos conjuntos con otras marcas de prestigio; calidad del servicio post-venta; políticas de precios... 
Pero todos esos procedimientos son en buena parte ajenos al producto; en efecto, las marcas pueden adquirir determinados atributos como consecuencia de una estrategia comercial y publicitaria que permite realizar asociación de ideas en cierto modo artificial: Pepsi significa inconformismo pese a que esa cualidad no es propia del sabor de la bebida de cola; y Benetton se asocia a ideas como provocación o fraternidad entre las razas, con independencia del tipo de ropa que fabrica esa firma italiana.

Cuando en un mercado compiten productos con poca capacidad de diferenciación, el modo más lógico de singularizarse -de buscar la diferencia- consiste en acudir a esas herramientas externas de construcción de marca. Cada compañía analiza cuál es el modo más eficiente de invertir recursos para lograr una determinada percepción en la mente de los consumidores (Murray, 2005).

Sin embargo, en el sector de la comunicación -y sobre todo en la prensa diaria de cobertura nacional- existen extraordinarias posibilidades de diferenciación de la oferta. Cada diario se distingue de sus competidores por su línea editorial, sus apuestas informativas, su calidad redaccional, el tamaño medio de sus noticias, su estructura interna, el modo de titular, sus columnistas, el tono de las historias, los suplementos, el porcentaje de superficie publicitaria, el tipo de anunciantes, el uso de la fotografía y las ilustraciones, el empleo del color, la calidad del papel, el diseño, el número de páginas, el formato...

Pero, además, los diarios cada día configuran su identidad: pueden variar levemente su perfil o, por el contrario, pueden reforzar la percepción de marca en la mente de sus lectores. La credibilidad ganada con muchos años de esfuerzo y rigor informativo se puede perder si se descubre que la dirección ha actuado al servicio de intereses ajenos, o no ha contrastado las fuentes, o ha actuado por animadversión o por amiguismo. Y, al contrario, el prestigio deteriorado se puede recomponer poco a poco con la precisión de los contenidos, con la publicación de primicias relevantes, con la valentía para publicar historias veraces e incómodas para los poderes políticos o económicos (Sancho, 2004).

Si el producto es diferenciado y cada día expresa públicamente sus convicciones y su interpretación de la realidad, las herramientas externas de construcción de marca sirven para reforzar una percepción, pero no para cambiarla por completo. Los mensajes contradictorios -los que se deducen de la lectura del diario y los que proceden del departamento de marketing- no sólo no son creíbles, sino que provocan confusión y desconfianza.

\subsection{Rasgos de identidad de El Mundo}

En el caso de El Mundo, los valores asociados a esa cabecera -independencia, atrevimiento, innovación, orientación liberal, capacidad de divertir y sorprender, periodismo de investigación e interés por las mani- 
festaciones culturales- provienen, sobre todo, del contenido del diario. El equipo directivo se ha empeñado en ser fiel a esos rasgos de identidad; ha sido consciente de que su éxito en buena parte dependía de no defraudar las expectativas de sus lectores.

Desde sus orígenes, el diario ha hecho pública su misión, con el fin de fijar su posición en el mercado y atraer a su público objetivo. Al poco tiempo de nacer, en su "Declaración de independencia" afirmaba: "El Mundo será un órgano radical en la defensa de sus convicciones, pero moderado y sereno en la exposición de sus argumentos. (...) Seremos intransigentes en cuanto a los derechos humanos, las libertades públicas, la dignidad de los consumidores, el respeto a la opinión de las minorías y la defensa del medio ambiente frente a la estupidez o la avaricia. (...) Creemos que la democracia española precisa de un profundo impulso regeneracionista que restituya a los ciudadanos el ejercicio práctico de la soberanía popular, secuestrada por las camarillas dirigentes de los grandes partidos y por los grupos de presión económica" (El Mundo, 1990, 3).

El diario de Unidad Editorial también ha construido su marca en los denominados "momentos de la verdad". Por ejemplo, continuó investigando a los Grupos Antiterroristas de Liberación (caso de los GAL) o el enriquecimiento ilícito del hermano del Vicepresidente del Gobierno (caso Juan Guerra), pese a que miembros del Gobierno y dirigentes del Partido Socialista denunciaron a El Mundo ante los tribunales. Aunque las sentencias siempre fueron favorables al periódico, era arriesgado publicar reportajes sobre esos hechos (García Alonso, 1995).

El Mundo ha tenido habilidad para mover la posición de sus principales rivales de la prensa madrileña: $E l$ País y ABC. Cuando criticaba al Partido Popular o al Gobierno conservador de Aznar, ponía de manifiesto su independencia del partido más cercano a su línea editorial, a diferencia de El País, que -a juicio del diario dirigido por Ramírez-identificaba su apuesta informativa con los intereses del Partido Socialista.

Con el conservador $A B C$, la estrategia de reubicación más destacada se produjo tras el gran atentado terrorista de Madrid ocurrido el 11 de marzo de 2004; ese trágico suceso tuvo una influencia notable en las elecciones generales que ganó tres días después el Partido Socialista. Del 11 al 14 de marzo, el Gobierno conservador de Aznar afirmó que los autores habían sido terroristas de ETA, y no terroristas islámicos que se vengaban de la participación española en la Guerra de Irak. En los meses posteriores a esa fecha, $A B C$ sostuvo que el Gobierno conservador se había equivocado, porque ETA no había participado en el atentado. En cambio, El Mundo afirmó repetidas veces que el Gobierno socialista no quería descubrir a los autores y cómplices de los atentados, y que la línea editorial de $A B C$ se estaba acercando extraordinariamente a la de El País; El Mundo publicó en varias ocasiones portadas con titulares similares de sus dos competidores, lo que le permitía situarse como la única oferta de centro-derecha crítica al Gobierno socialista. 
El Mundo ha sido acusado de parcialidad (Cebrián, 1997): de situarse excesivamente cerca del Partido Popular y de oponerse de modo permanente al Partido Socialista. Sin embargo, atacó sin ambages -quizás más que ningún otro diario- la decisión del Gobierno de Aznar de enviar tropas españolas a la guerra de Irak; y mantuvo una posición de respeto esperanzado durante los primeros 18 meses del Gobierno socialista presidido por Zapatero. Esas decisiones editoriales le han dado más credibilidad y han reforzado su reputación de publicación independiente.

\section{Explotar las fortalezas}

\subsection{Las "apuestas editoriales"}

El Mundo ha sido capaz de explotar de modo eficiente sus fortalezas y de minimizar el impacto negativo de sus debilidades. En el terreno de los puntos fuertes, la dirección del periódico ha logrado sacar el máximo partido a las primicias descubiertas por sus equipos de investigación, con una excelente administración de los tiempos.

La "explotación de la primicia" suele seguir las siguientes pautas: el director es entrevistado en otros medios -casi siempre en emisoras de radio y canales de televisión- en los que explica que los periodistas de su diario han descubierto documentos o pruebas que indican un comportamiento ilegal o inmoral de un personaje relevante en la opinión pública (casi siempre un político); la persona aludida defiende su inocencia y acusa al director de El Mundo de mentir; el diario comienza a publicar informaciones -entrevistas, datos, fotografías, documentos, etc.- pero no muestra los hechos más comprometedores para el protagonista de la noticia; el debate sube de tono, y la parte acusada denuncia ante los tribunales al periódico; al cabo de unos días o semanas de polémica, El Mundo publica las pruebas más concluyentes en las que se basa su denuncia y da por terminada la historia.

Por tanto, se produce una cierta adecuación del relato al interés comercial -incremento de la venta de ejemplares-y a la oportunidad política: deterioro del prestigio de personajes políticos cuya actuación es juzgada negativamente por el diario; como contrapartida, existe el riesgo de que, en ese proceso, se "fuercen los hechos”, en una línea de trabajo cercana al sensacionalismo. Como es sabido, uno de los viejos axiomas del periodismo amarillo afirma que la noticia nunca debe estropear un buen titular (Campbell, 2001).

En todo caso, con esa secuencia temporal, el periódico consigue dar continuidad a la historia y aumenta el número y la frecuencia de compra de los lectores, que no quieren perderse los sucesivos capítulos de la na- 
rración. Por otra parte, su denuncia no pasa inadvertida junto a otros cientos de noticias publicadas cada día en las páginas del diario: al apostar por un acontecimiento de calado político, se convierte en una publicación relevante, capaz de modificar la agenda de temas de discusión.

El Mundo ha destacado también por el protagonismo de sus enviados especiales en los principales conflictos bélicos del mundo. Su sección de noticias internacionales cuenta con menos redactores y con menos páginas que competidores como El País, ABC o La Vanguardia: el diario de Unidad Editorial elige pocos temas de interés, pero los cubre en profundidad y con un estilo periodístico caracterizado por las entrevistas, reportajes y narraciones en primera persona; de ese modo acerca a sus lectores los acontecimientos lejanos.

Los periodistas de El Mundo en los conflictos bélicos han destacado por su arrojo y valentía. Dos enviados especiales fallecieron en sendas guerras: Julio Fuentes, en 2001, en Afganistán; y José Julio Parrado, en 2003, en Irak.

El diario también ha concedido gran importancia a los contenidos sobre educación y cultura, adecuados al perfil joven y urbano de sus lectores. Los suplementos semanales "Campus" -sobre enseñanza media y universitaria- y “Metrópoli” -con reseñas de las principales ofertas culturales de Madrid-han sido pioneros en su género.

Con su orientación editorial y su estrategia informativa, ha conseguido construir una personalidad propia. La apuesta por el periodismo de investigación, los enviados especiales a los conflictos bélicos y su interés por el mundo de la cultura, la educación y la comunicación han contribuido a configurar su marca: $E l$ Mundo está vinculado a atributos como iniciativa, atrevimiento, investigación, anticipación, exclusividad, cultura y denuncia de los excesos del poder establecido (Unidad Editorial, 2007).

Esos rasgos distintivos del perfil editorial del periódico le han convertido en una de las opciones informativas con más éxito entre los jóvenes. Teniendo en cuenta ese público objetivo, el diario de Unidad Editorial ha invertido notables recursos en aspectos gráficos y de diseño. Los promotores eligieron un formato tabloide, pero levemente más ancho que el estándar -60 centímetros en vez de 57- para diferenciarse y para lograr un mayor impacto visual de las fotografías e infográficos. La superficie manchada no está muy recargada, para que las páginas "respiren" en su estructura de cinco columnas.

La portada refleja la apuesta editorial del día. Siguiendo el estilo clásico del "tabloide cartel”, casi siempre la noticia principal se publica a cuatro columnas. Como explica el primer director de arte del periódico, esa decisión es apropiada cuando la noticia de apertura es muy relevante; pero en otras ocasiones, "puede parecer que la historia está un poco hinchada" (Caderot, 1993: 274). 
Ya en 1991, y pese a la debilidad económica de aquellos primeros años, El Mundo obtuvo varios galardones de la Society of Newspaper Design (SND), hecho que volvería a repetirse en las convocatorias siguientes. El diario, para dar valor a los premios logrados, explicaba a sus lectores que se trataban de los "Pulitzer de la ilustración y el diseño”: es decir, el reconocimiento más valioso referido al periodismo gráfico a nivel internacional.

\subsection{Neutralizar las debilidades}

En parte, las apuestas de El Mundo han estado condicionadas por sus debilidades: como carecía de recursos para contratar un elevado número de corresponsales en el extranjero, se limitaba a enviar periodistas a los lugares de conflicto; como su plantilla era menos numerosa que la de sus competidores, decidía concentrar sus esfuerzos en unos pocos temas diarios; como no podía ser tan completo como El País o ABC, empleaba un tono informativo más atrevido; como carecía de la variedad y diversidad de medios de los grandes grupos españoles de comunicación, se aliaba con otras empresas independientes -en particular con la compañía de radio COPE- para hacer promociones cruzadas y coberturas informativas conjuntas; y -sobre todo en sus primeros años- aprovechó que tenía menos publicidad y que procesaba menos información que sus rivales para superarles en los elementos gráficos y visuales de sus páginas.

El equipo de Pedro J. Ramírez ha desplegado una extraordinaria habilidad para convertir los problemas en oportunidades. Detrás de ese enfoque se esconde un estilo directivo optimista, que no se paraliza al detectar las propias debilidades y que está enfocado a imponer las reglas del juego que más le convienen. Ese talante, de consecuencias muy favorables para el trabajo creativo (Staw, Sutton y Pellod, 1994; Becker et al, 2007), constituye un activo inmaterial que ha permitido neutralizar las desventajas económicas y financieras de Unidad Editorial.

Los directivos de El Mundo han distinguido los elementos “críticos" de los "higiénicos”. De los primeros dependían la diferenciación, la exclusividad y las señas de identidad del periódico: en esos aspectos era necesario lograr la excelencia porque constituían las principales razones de compra y lectura del periódico (estrategia de ataque); en cambio, en los aspectos "higiénicos" bastaba con alcanzar un nivel de calidad aceptable, para atenuar puntos débiles o carencias de las que podía depender una percepción negativa de los lectores potenciales (estrategia de defensa). Con la consolidación económica de Unidad Editorial, sobre todo a partir de 2002, El Mundo ha reformulado su modo de competir, pero ha mantenido los principales valores de su marca. 


\section{Un diario coherente}

\subsection{Protección estratégica de la marca}

Uno de los aspectos más sobresalientes de la trayectoria de El Mundo es su coherencia. Ese rasgo de la personalidad del periódico contribuye a configurar el perfil tan definido de su marca. Por ejemplo, la debilidad de Unidad Editorial en el ámbito audiovisual es a la vez signo y consecuencia de su independencia: como el diario es crítico con el poder, apenas ha recibido licencias de radio y televisión de las muchas que han otorgado los gobiernos españoles durante las últimas dos décadas.

En la junta general de accionistas de 2007 Pedro J. Ramírez se quejaba de ese hecho, que generaba una desventaja competitiva frente a otros grupos de comunicación beneficiados por las recientes concesiones administrativas (El Mundo, 30.VI.2007: 68): "Parece que ni los gobiernos de derechas ni los de izquierdas se han fiado de Unidad Editorial (...). Es un síntoma de que los gobiernos no sólo piden que no se les trate mal, sino que pretenden que se les trate extraordinariamente bien".

Unidad Editorial ha hecho campaña para que las concesiones de emisoras de radio y canales de televisión no las otorguen los gobiernos sino comisiones independientes. Pero mientras no se produce ese cambio legal, la compañía no está dispuesta a comprometer su independencia a cambio de favores políticos. También pone sus esperanzas en el desarrollo de la tecnología digital, que incrementará el número de operadores y disminuirá la capacidad de los gobiernos para regular el mercado audiovisual.

La coherencia de El Mundo se manifiesta también en sus promociones editoriales. Las promociones de la prensa se proponen dos posibles objetivos (Lacy \& Davenport, 1994): a) incrementar las ventas de los diarios mediante un producto añadido gratuito o a muy bajo precio, que haga la oferta más atractiva; b) rentabilizar la marca (que actúa como prescriptor de compra) y la cadena de distribución, con la venta de productos que - por ser producidos a gran escala- tienen un margen muy elevado para las empresas editoras. En ocasiones es posible lograr ambos objetivos a la vez: aumentar la difusión y obtener ingresos adicionales a la venta de ejemplares y de publicidad.

Los competidores de El Mundo han regalado o vendido productos poco relacionados con la oferta editorial para evitar el estancamiento de la difusión o para mejorar sus ingresos: han distribuido vajillas, toallas para la playa, balones de fútbol, MP3, mochilas o instrumentos de cocina. Durante el mes de junio de $2005 \mathrm{La}$ Razón llegó a regalar dos croissants a cada comprador del periódico, con el fin de "premiar la fidelidad de los lectores". 
En cambio, el diario de Unidad Editorial se ha limitado a ofrecer productos que encajaban bien con su marca: enciclopedias, libros de bolsillo, vídeos de películas clásicas del siglo XX, fascículos coleccionables de historia de España, láminas de pintores contemporáneos... Es decir, no ha renunciado a las promociones, pero ha hecho compatible esa estrategia de marketing con la protección de los valores que están asociados a su nombre comercial.

De modo coherente con la historia épica de Robin Hood, que se opone a los poderosos para defender a los desvalidos, El Mundo ha sido pionero en la apuesta por la interactividad en la prensa española: el protagonismo no corresponde a las fuentes interesadas, a los departamentos de comunicación de las empresas y de los partidos políticos sino a los ciudadanos. Con esa percepción de la realidad, desde 1996 los directivos del diario de Unidad Editorial han utilizado las posibilidades de participación que ofrece internet para solicitar el punto de vista del público.

La conexión entre El Mundo y elmundo.es permite que los ciudadanos opinen sobre las informaciones y artículos, comenten aspectos mejorables del producto o participen en votaciones y chats. Como sucede en otros mercados (Pauwels y Kans, 2001), la interactividad y la promoción cruzada entre las versiones impresa y on line del diario fomentan el incremento del número de lectores y refuerzan la lealtad a la marca.

El Mundo ha continuado su política de acercamiento a los lectores con el lanzamiento de siete ediciones regionales. Esas ediciones tienen contenidos comunes -que ocupan más del $70 \%$ de la superficie impresa- y contenidos específicos: noticias y anuncios de carácter local. La proximidad geográfica ha favorecido el incremento de la difusión, de los ingresos publicitarios y de la satisfacción del público (Unidad Editorial, 2007).

\subsection{Diversificación y crecimiento}

También la política de diversificación y crecimiento refleja el comportamiento coherente del periódico, basado en su misión y en la percepción de la marca por parte de los lectores. Con el éxito de El Mundo, los directivos de Unidad Editorial consideraron que tenían la posibilidad de aprovechar el prestigio y los recursos generados para lanzar nuevas ofertas. En casi todos los casos, esos nuevos productos y servicios han compartido las señas de identidad del diario.

La estrategia de diversificación ha permitido que la empresa editora de El Mundo desarrolle con notable éxito varias unidades de negocio: Mundinteractivos, que es la división de contenidos on line, en la que destaca elmundo.es; El Mundo TV, productora dedicada a periodismo de investigación; La Esfera de los Libros, 
sello editorial que publica libros de no ficción, y que toma el nombre del logotipo del periódico (una esfera del mundo); y la división de revistas, con títulos como La Aventura de la Historia, Descubrir el Arte, Siete Leguas (viajes) y OKS (salud).

En cambio, el perfil editorial de El Mundo es tan nítido que el público no ha aceptado sus tímidas propuestas en el sector del entretenimiento. Parece que los lectores han considerado que el diario estaba fuera de su sitio -realizando una tarea poco adecuada a sus habilidades y experiencias- cuando ha producido películas o contenidos televisivos de ficción. Tras esos fracasos, Unidad Editorial ha dirigido sus nuevos proyectos al ámbito de la información. En ese contexto se entiende la adquisición del grupo Recoletos en 2007, compañía dedicada a la edición de diarios y revistas especializadas, y que comparte muchas de las señas de identidad de El Mundo.

Los estudios que Unidad Editorial encarga periódicamente a la empresa de sondeos CIMOP confirman que la imagen de El Mundo corresponde a los valores que han tratado de defender los promotores del periódico. Como se observa en las siguientes tablas, el periódico es percibido como un producto con personalidad, audaz, orientado a la investigación y capaz de crear opinión, aunque no demasiado objetivo; la característica que más se destaca de su director es la profesionalidad; la mayoría de sus lectores califican a El Mundo como bueno (62\%) o muy bueno (19\%); y quienes han dejado de leerlo aducen motivos variados: ha dejado de gustarles, es demasiado partidario del gobierno, les aburre o prefieren informarse por otros medios.

Tabla I. Factores que configuran la personalidad de El Mundo

\begin{tabular}{|l|l|}
\hline Mucho 4 Pastante 3 Poco 2 Nada 1 & MEDIA \\
\hline Personalidad periodística & 3,12 \\
\hline Audacia informativa & 3,09 \\
\hline Periodismo de investigación & 3,07 \\
\hline Capacidad para crear opinión & 3,05 \\
\hline Credibilidad informativa & 2,97 \\
\hline Liderazgo mediático & 2,92 \\
\hline Entretenimiento & 2,80 \\
\hline Pluralidad de puntos de vista & 2,75 \\
\hline Diversidad de enfoques & 2,74 \\
\hline
\end{tabular}




\begin{tabular}{|l|c|}
\hline Independencia de juicio & 2,71 \\
\hline Actitud crítica hacia todos los poderes & 2,65 \\
\hline
\end{tabular}

Fuente: CIMOP, 2004. Encuesta realizada a 1033 personas que declaraban ser lectores habituales u ocasionales de El Mundo.

Tabla II. Los principales defectos de $E l$ Mundo, según sus lectores (respuestas espontáneas)

\begin{tabular}{|l|c|}
\hline & \% Base (1.033) \\
\hline Partidista/parcial/poco objetivo & 35,2 \\
\hline Suplementos & 14,0 \\
\hline Falta de crítica & 13,2 \\
\hline Formato & 10,5 \\
\hline Amarillista/protagonista & 8,6 \\
\hline Demasiado extenso/mucho texto & 7,6 \\
\hline Tratamiento/enfoque reiterado & 6,5 \\
\hline La dirección & 4,3 \\
\hline NS & 6,1 \\
\hline Demasiada publicidad & 4,1 \\
\hline
\end{tabular}

Fuente: CIMOP, 2004.

Tabla III. Opiniones sobre el director de El Mundo

\begin{tabular}{|l|c|}
\hline & \% Base (1.033) \\
\hline Profesional & 25,9 \\
\hline Le gusta & 18,2 \\
\hline No le gusta & 14,7 \\
\hline Personalista & 12,0 \\
\hline Partidista & 6,7 \\
\hline Prepotente & 3,9 \\
\hline Honesto & 2,8 \\
\hline
\end{tabular}




\begin{tabular}{|l|c|}
\hline Valiente & 2,3 \\
\hline Indiferencia & 2,1 \\
\hline Inteligente & 2,0 \\
\hline No tiene opinión & 7,4 \\
\hline NC & 2,0 \\
\hline
\end{tabular}

Fuente: CIMOP, 2004.

Figura 1. Imagen y posicionamiento de los diarios nacionales para los lectores de $E l$ Mundo

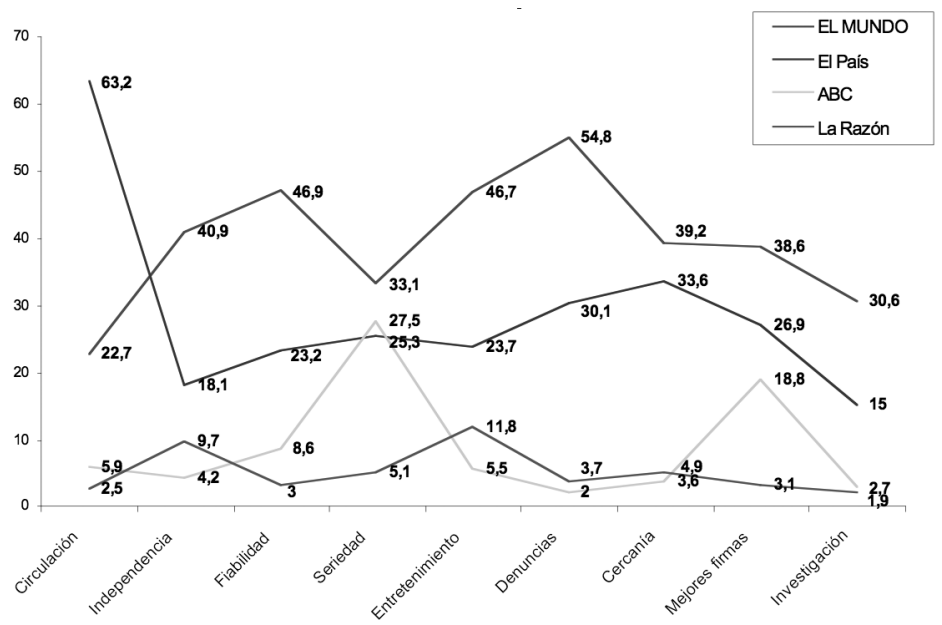

Fuente: CIMOP, 2004.

Tabla IV. Valoración de El Mundo según sus lectores Usted diría que actualmente $E l$ Mundo es un diario...

\begin{tabular}{|l|c|}
\hline & \% Base (1.033) \\
\hline Excelente (6) & 3,8 \\
\hline Muy bueno (5) & 19,0 \\
\hline Bueno (4) & 62,1 \\
\hline Regular (3) & 13,4 \\
\hline
\end{tabular}




\begin{tabular}{|l|c|}
\hline Malo (2) & 1,7 \\
\hline Muy malo (1) & 0,1 \\
\hline MEDIA & 4.09 \\
\hline
\end{tabular}

Fuente: CIMOP, 2004.

Tabla V. Los que dejaron de comprar El Mundo explican sus motivos

\begin{tabular}{|l|c|}
\hline MOTIVOS & \% Base (130) \\
\hline Dejó de gustar & 29,2 \\
\hline Partidista/falta objetividad/pro gobierno & 17,7 \\
\hline Compra otro periódico & 17,7 \\
\hline Cansancio/aburrimiento & 13,1 \\
\hline Se informa por otros medios & 12,3 \\
\hline Acabó la promoción de su interés & 4,6 \\
\hline Lo lee en Internet & 2,3 \\
\hline
\end{tabular}

Fuente: CIMOP, 2004.

Tabla VI. El Mundo según sus lectores

\begin{tabular}{|l|c|}
\hline Características del diario: es... & \% Base (500) \\
\hline El que más investiga & 68,8 \\
\hline Abierto a diferentes puntos de vista & 53,8 \\
\hline Serio en ofrecer la información & 53,1 \\
\hline Completo & 51,8 \\
\hline Creíble & 47,6 \\
\hline Entretenido & 40,6 \\
\hline
\end{tabular}

Fuente: CIMOP, 2005.

Tungate (2004) explica que los medios que pretenden construir marcas sólidas necesitan una referencia clara: una visión que dé coherencia a la trayectoria de la compañía. Los directivos de El Mundo han contado con ese punto de partida; y han conseguido que un pequeño diario, que nació hace menos de dos décadas, 
casi sin recursos y en un mercado muy competitivo, se haya convertido en una de las marcas más valoradas e influyentes del panorama periodístico español.

\section{Referencias bibliográficas}

Aaker, D. A. (1991): Managing Brand Equity: Capitalizing on the Value of a Brand Name. Nueva York: Free Press.

Arvidsson, A. (2005): Brands: Meaning and Value in Post-Modern Media Culture. Londres: Routledge.

Becker, L. B. et al. (2007): “The Impact of Internal Labor Markets on Newspaper Industry Personnel Practices”, The International Journal on Media Management, 9 (2), 59-69.

Caderot, C., cit. por J. I. Armentia (1993): Las nuevas tendencias en el diseño de la prensa española a finales de los 90: el cambio de "La Vanguardia" y la aparición de "El Mundo". Bilbao: tesis doctoral, Universidad del País Vasco.

Campbell, W. J. (2001): Yellow Journalism: Puncturing the Miths, Defining the Legacies. Westport (CT): Praeger Publishers.

Cebrián, J. L. (1997): Cartas a un joven periodista. Barcelona: Planeta.

Danesi, M. (2006): Brands. Londres: Routledge.

Edo, C (1994): La crisis de la prensa diaria. La línea editorial y la trayectoria de los periódicos de Madrid. Barcelona: Ariel Comunicación.

Elliot, R. H. y L. Percy (2007): Strategic Brand Management. Oxford: Oxford University Press.

El Mundo (15.XII.1990): Declaración de independencia, 3.

El Mundo (30.VI.2007): Unedisa ha muerto, viva Unidad Editorial, 68.

Financial Times (26.V.1993): Enemy of the People in Power.

García Alonso, P. (1995): El Mundo del siglo XXI (1989-1994). Unidad Editorial S. A.: lanzamiento y desarrollo de una empresa informativa. Madrid: tesis doctoral, Universidad Complutense de Madrid.

Holdt, D. B. (2004): How Brands Become Icons: the Principles of Cultural Branding. Boston: Harvard Business School Press.

Kung, L. (ed.) (2006): Leadership in the Media Industry: Changing Contexts, Emerging Challenges. Jonköping: Jonköping International Business School.

Lacy, S. y L. Davenport (1994): “Daily Newspaper Market Structure, Concentration and Competition”, Journal of Media Economics, 7 (3), 33-46.

Mardones, I. (30.X.1989): “Sale El Mundo, sexto diario de Madrid, dirigido por Pedro J. Ramírez”, El País.

Millar, J. y D. Muir, (2004): The Business of Brands. Chichester: Wiley. 
Murray, S. (2005): "Brand Loyalties: Rethinking Content within Global Corporate Media”, Media Culture \& Society, 27 (3), 415-435.

Noticias de la Comunicación (23.X.1991): Elegido el nuevo consejo de administración de Unidad Editorial, nº 23, 3.

Pauwels, K. y E. Dans (2001): “Internet Marketing the News : Leveraging Brand Equity from Marketplace to Marketspace”, The Journal of Brand Management, 8 (4), 303-314.

Ramírez, P. J. (1980): Prensa y Libertad. Madrid: Institución Economía y Mercado.

Ramírez, P. J., con M. Robles, (1991): El Mundo en mis manos. Barcelona: Grijalbo.

Sancho, F. (2004): En el corazón del periódico. Pamplona: EUNSA.

Staw, B., R. Sutton y L. Pellod (1994): "Employee Positive Emotion and Favorable Outcomes at the Workplace", Organizational Science, 5, 51-71.

Tungate, M. (2004): Media Monolitos: How Great Media Brands Thrive and Survive. Londres: Kogan Page.

Unidad Editorial (2007): Informe anual. Madrid. 